\title{
Parallelism between Avoidance-Suppressing and Prolactin- Increasing Effects of Antipsychotic Drugs in Rats
}

\author{
Tetsu HAYASHI and Sakutaro TADOKORO \\ Behavioral Research Institute, Gunma University School of Medicine, Maebashi 371, Japan \\ Accepted May 10, 1984
}

\begin{abstract}
Temporal changes in the avoidance responses and serum prolactin levels were investigated for a $360 \mathrm{~min}$ period after s.c. administration of antipsychotic drugs such as chlorpromazine $(2 \mathrm{mg} / \mathrm{kg}$ ), prochlorperazine $(2 \mathrm{mg} / \mathrm{kg})$, haloperidol $(0.035 \mathrm{mg} / \mathrm{kg})$, droperidol $(0.03 \mathrm{mg} / \mathrm{kg}), \mathrm{YM}-09151-2(0.005 \mathrm{mg} / \mathrm{kg})$ and sulpiride $(80 \mathrm{mg} / \mathrm{kg})$ in rats. Male adult rats of the Wistar strain were trained under a continuous lever-press avoidance schedule (Sidman type) to observe avoidancesuppressing effects of the drugs. The avoidance response was suppressed after administration of chlorpromazine, prochlorperazine, haloperidol, droperidol and YM-09151-2, showing significant decrease in response rate and significant increase in shock rate when compared with those after saline administration, while it was scarcely suppressed within 150 min after sulpiride. On the other hand, serum prolactin levels were increased after administration of all the drugs used. Furthermore, parallelism between temporal changes in the avoidance responses and those in serum prolactin levels was observed after administration of the antipsychotic drugs, except for sulpiride. These results suggest that the prolactin-increasing effects of antipsychotic drugs are applicable for predicting antipsychotic efficacies in humans, excluding sulpiride therapy.
\end{abstract}

Conditioned avoidance responses of rats have been widely applied to preclinical tests of antipsychotic drugs because of the high correlation between the avoidancesuppressing effects observed in animals and antipsychotic potencies in man $(1,2)$.

On the other hand, prolactin secretion is markedly stimulated by the antipsychotic drugs in animals and man (3-6). It is, therefore, important to investigate the relationship between avoidance-suppressing and prolactin-increasing effects of the antipsychotic drugs. However, there are few reports concerned with this problem.

In the present study, the systematic correlation between temporal changes in avoidance response and those in serum prolactin level was investigated after administration of antipsychotic drugs such as phenothiazine, butyrophenone and benzamide derivatives in rats.

\section{Materials and Methods}

Animals: Animals used were 555 male rats of the Wistar strain weighing 260-270 g. The animals were supplied by the Institute of Experimental Animal Research of Gunma University School of Medicine. Rats were housed in groups of 5-6 in stainless steel wire mesh cages with dimensions of $38(D)$ $\times 25(\mathrm{~W}) \times 20(\mathrm{H}) \mathrm{cm}$, and they had free access to a solid diet of MF (Oriental Yeast Co., Tokyo) and tap water. The animals were kept in a room at $24 \pm 2{ }^{\circ} \mathrm{C}$ with a $12 \mathrm{hr}$ lightdark cycle (fluorescent illumination on 6:0018:00). However, the humidity was not controlled. All experiments were conducted between 10:00-16:00, taking account circadian periodicity in prolactin secretion (7).

Continuous lever-press avoidance schedule (Sidman type): Seven rats were trained to avoid an electroshock by pressing a lever in an operant chamber which was enclosed in a ventilated sound-attenuating box. The avoidance schedule consisted of a $30 \mathrm{sec}$ response-shock interval and a 5 sec shockshock interval. The electroshocks of $110 \mathrm{~V}$. 
$0.5 \mathrm{~mA}, 50 \mathrm{~Hz}$ AC were delivered for $0.3 \mathrm{sec}$ through the floor grids.

Each session consisted of $1 \mathrm{hr}$ training per day, and the training was held every other day for at least 20 sessions until establishment of the behavioral baseline. The indices for the evaluation of avoidancesuppressing effect were the response rate (no. of lever-pressings/min) and the shock rate (no. of shocks delivered/min). The rats which exhibited response rates of 12 and shock rates of less than 0.2 for more than 5 consecutive sessions were subjected to a drug test. According to our previous report, the behavioral baseline, once established, was stable throughout the continuous $6 \mathrm{hr}$ observation after saline administration (8).

Each drug was administered s.c. immediately before the test, and temporal changes in avoidance response at a $10 \mathrm{~min}$ segment were recorded for $360 \mathrm{~min}$. The drug test was done once a week. Data were taken from animals exposed to sufficient drug experiences (at least 5 times) to show a stable susceptibility to the drugs because avoidance-suppressing effects of antipsychotic drugs are sometimes weak and unstable when the drugs are given to drugnaive rats (9).

Behavior controlling and recording apparatuses (GT 7705 and GT 7715, O'Hara Co., Ltd., Tokyo) were placed in a separate room.

Serum prolactin levels: In order to investigate temporal changes in serum prolactin level after antipsychotic drugs, 13 groups (7 rats/ group), different from the avoidance experiment group, were prepared for each drug test including the saline test. At intervals of 30 min after the drug administration, one group of rats sacrificed by decapitation and blood samples were collected over a $360 \mathrm{~min}$ period.

Prolactin was assayed by double antibody radioimmunoassay according to the recommendations supplied with the NIAMDD kit. All samples were assayed in triplicate. Prolactin levels were expressed as $\mathrm{ng} / \mathrm{ml}$ of NIAMDD rat PRL-RP-1. The intraassay variability was $5 \%$.

Drugs used: Chlorpromazine (CPZ) (Contomin ${ }^{\circledR}$, Inj., Yoshitomi), $2 \mathrm{mg} / \mathrm{kg}$; prochlorperazine (PCZ) (Novamin ${ }^{\circledR}$, Inj., Shionogi), $2 \mathrm{mg} / \mathrm{kg}$; haloperidol (HPD) (Serenace ${ }^{\circledR}$, Inj., Dainippon), 0.035 mg/kg; droperidol (DPD) (Droleptan ${ }^{\circledR}$, Inj., Sankyo), 0.03 mg/kg; YM-09151-2 (YM) (Powder, Yamanouchi), $0.005 \mathrm{mg} / \mathrm{kg}$; and sulpiride (SP) (Dogmatyl ${ }^{\circledR}$, Inj., Fujisawa), $80 \mathrm{mg} / \mathrm{kg}$ were used. According to our reports, the doses used were optimum for observing typical avoidance-suppressing effect without cataleptic symptom in rats (10-12).

YM-09151-2 (cis-N-(1-benzyl-2-methylpyrrolidin-3-yl)-5-chloro-2-methoxy-4-

methylaminobenzamide), one of the benzamide derivatives which induce strong avoidance suppression (12, 13), was dissolved in a few drops of $1 \mathrm{~N} \mathrm{HCl}$ with subsequent dilution with saline solution. CPZ, PCZ, HPD and DPD were dissolved in saline solution. The commercial preparation of SP was used without any treatment. Doses were made up to the volume of $1 \mathrm{ml} / \mathrm{kg}$ of body weight, except in the case of SP (1.6 $\mathrm{ml} / \mathrm{kg}$ ).

Statistical analysis: Results obtained were analyzed by one way ANOVA followed by Student's $t$-test. They were considered significant when $\mathrm{P}$ was equal to or less than 0.05 .

\section{Results}

The avoidance response was markedly suppressed immediately after s.c. administration of CPZ, PCZ, HPD, DPD and YM, showing significant decrease in response rate and significant increase in shock rate when compared with those after saline administration. The temporal patterns of response rate and shock rate were diverse according to the drug species as shown in Figs. 1, 2 and 3. The avoidance-suppressing effect produced by SP was different from those produced by the other drugs. The onset time of the effect was delayed markedly and significant increase in shock rate was observed 150 min after the drug administration as shown in right-lower panel of Fig. 3.

On the other hand, serum prolactin levels were increased significantly after all drug administrations when compared with those obtained by saline administration. Further- 

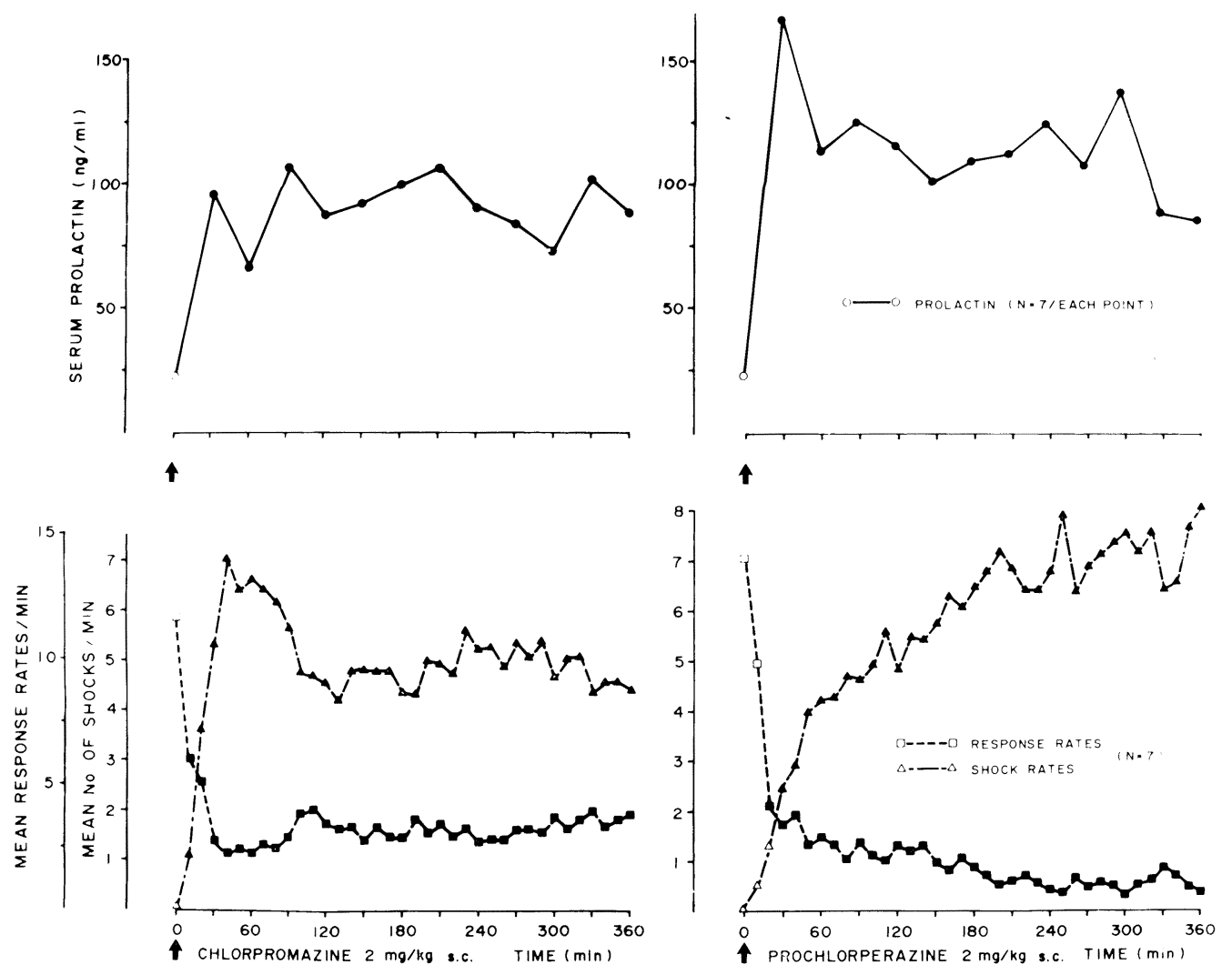

Fig. 1. Temporal changes in avoidance responses (lower panel) and serum prolactin levels (upper panel) after administration of phenothiazine derivatives: chlorpromazine (2 mg/ $\mathrm{kg} \mathrm{s.c.)} \mathrm{(left} \mathrm{panel)} \mathrm{and}$ prochlorperazine (2 $\mathrm{mg} / \mathrm{kg}$ s.c.) (right panel). In the upper panel, each point indicates an average prolactin level obtained in 7 rats after saline (only the initial point), chlorpromazine and prochlorperazine administration. Closed symbol means significant difference from the initial level (time 0) obtained by saline administration. Closed symbols $\boldsymbol{\Delta}, \boldsymbol{\Delta}$ mean significant differences from the initial values before the drug administration (time 0).

more, the temporal changes in prolactin levels after administration of the antipsychotic drugs seemed to be almost proportional to the increase in shock rate and opposite to the decrease in response rate, except for the SP-given case, as shown in Figs. 1, 2 and 3. The serum prolactin level was elevated rapidly after SP administration, but no parallelism between temporal changes in avoidance response and those in serum prolactin level was observed, as shown in the right-upper panel of Fig. 3.

\section{Discussion}

Avoidance responses of rats are suppressed almost selectively and dose-dependently by antipsychotic drugs (10). On the other hand, prolactin secretion from the anterior pituitary gland is inhibited by dopamine or it's agonists (14-21), and on the contrary, it is stimulated by dopamine blocking agents such as antipsychotic drugs in a dose-dependent manner both in animals and man (3-6). Furthermore, no tolerance is observed to the drug-induced increase in prolactin level when the drugs are administered repeatedly (3).

The results obtained in the present study showed that there was a parallelism between temporal changes in avoidance responses and those in serum prolactin levels after administration of the antipsychotic drugs, except for SP. The avoidance-suppressing effect of SP 

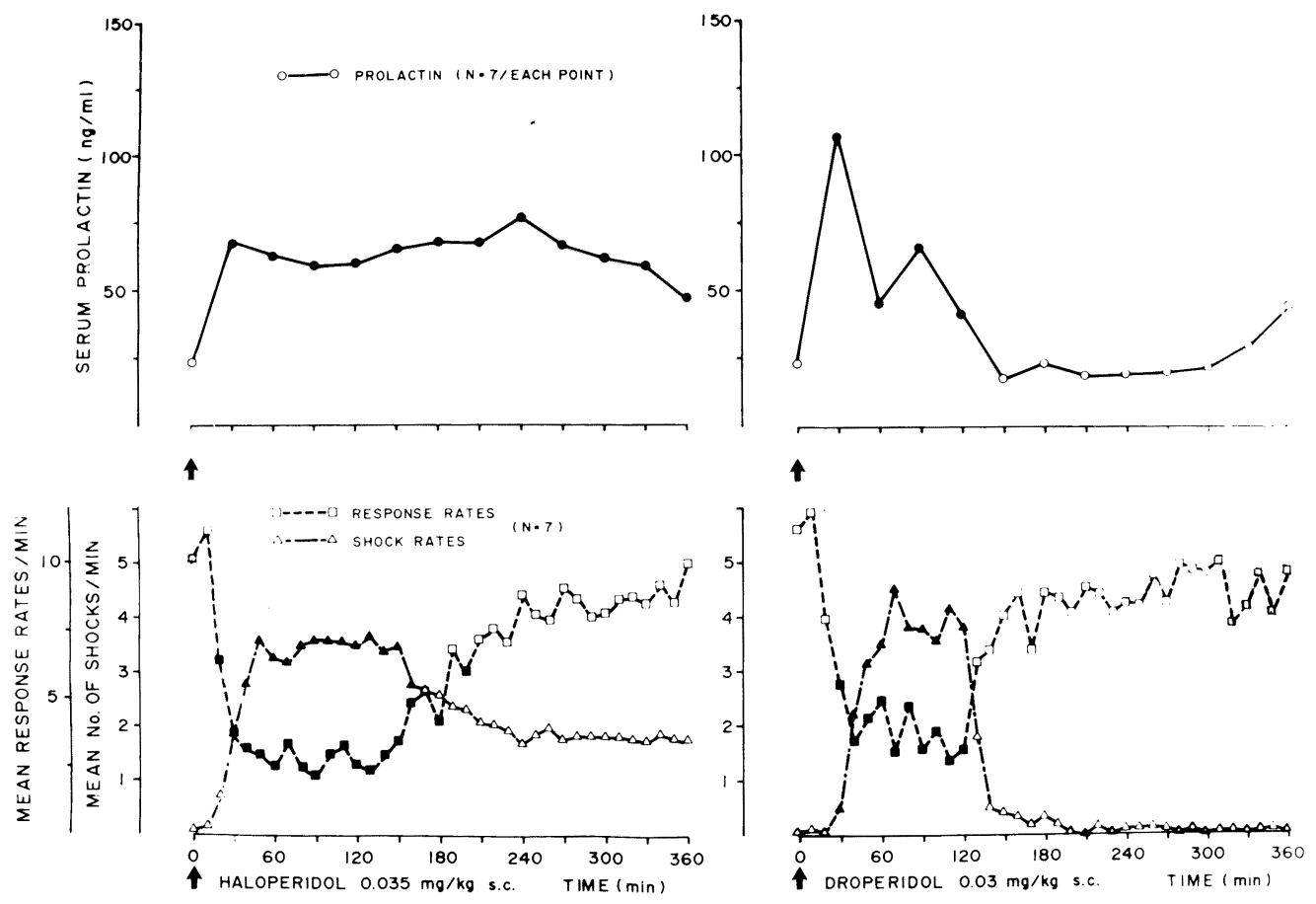

Fig. 2. Temporal changes in avoidance responses (lower panel) and serum prolactin levels (upper panel) after administration of butyrophenone derivatives: haloperidol $(0.035 \mathrm{mg} / \mathrm{kg} \mathrm{s.c.)}$ (left panel) and droperidol $(0.03 \mathrm{mg} / \mathrm{kg}$ s.c.) (right panel). The data are shown in the same way as in Fig. 1.

was elicited very slowly, and it was observed at $150 \mathrm{~min}$ after the administration and thereafter, while the serum prolactin level was rapidly elevated after the drug administration.

It is well known that SP, a $D_{2}$ blocking agent (22), elicits little effect on avoidance responses (11-13). Kuribara and Tadokoro (11) investigated the avoidance-suppressing effects of 28 kinds of antipsychotic drugs on both continuous and discriminated avoidance responses in rats over a $120 \mathrm{~min}$ period. In these experiments, little avoidance-suppressing effect of SP was seen independently of the experimental schedules used. The similar effect of SP on discriminated avoidance response was also reported by Usuda et al. (13).

On the other hand, Honda et al. (23) investigated apomorphine- and methamphetamine-induced gnawing and rotational behaviors in naive and in substantia nigralesioned rats, respectively, after oral and intraventricular administration of CPZ, HPD and SP. In this study, they reported that SP had essentially a potent inhibitory effect on dopaminergic neurons in the brain and that the weak central effects of SP given peripherally might be due to poor penetration through the blood-brain barrier. This hypothesis is also confirmed by the investigations of Hopf and Dross (24) and Benakis and Rey (25). These possibilities indicate that the slow onset of the avoidance-suppressing effect of SP observed in the present study is probably not due to the experimental procedure used, but rather due to the ability of the drug to hardly cross the blood-brain barrier. Actually, YM (a similar $\mathrm{D}_{2}$ blocking agent that is a benzamide derivative), (22) which can readily pass through the barrier and exhibits potent avoidance-suppressing effect $(12,13)$, showed almost parallel avoidance suppression to the increase in serum prolactin level in the present study.

There are many reports which emphasize the potent effect of SP on prolactin secretion both in serum and cerebrospinal fluid in animals and psychotic patients (26). This 

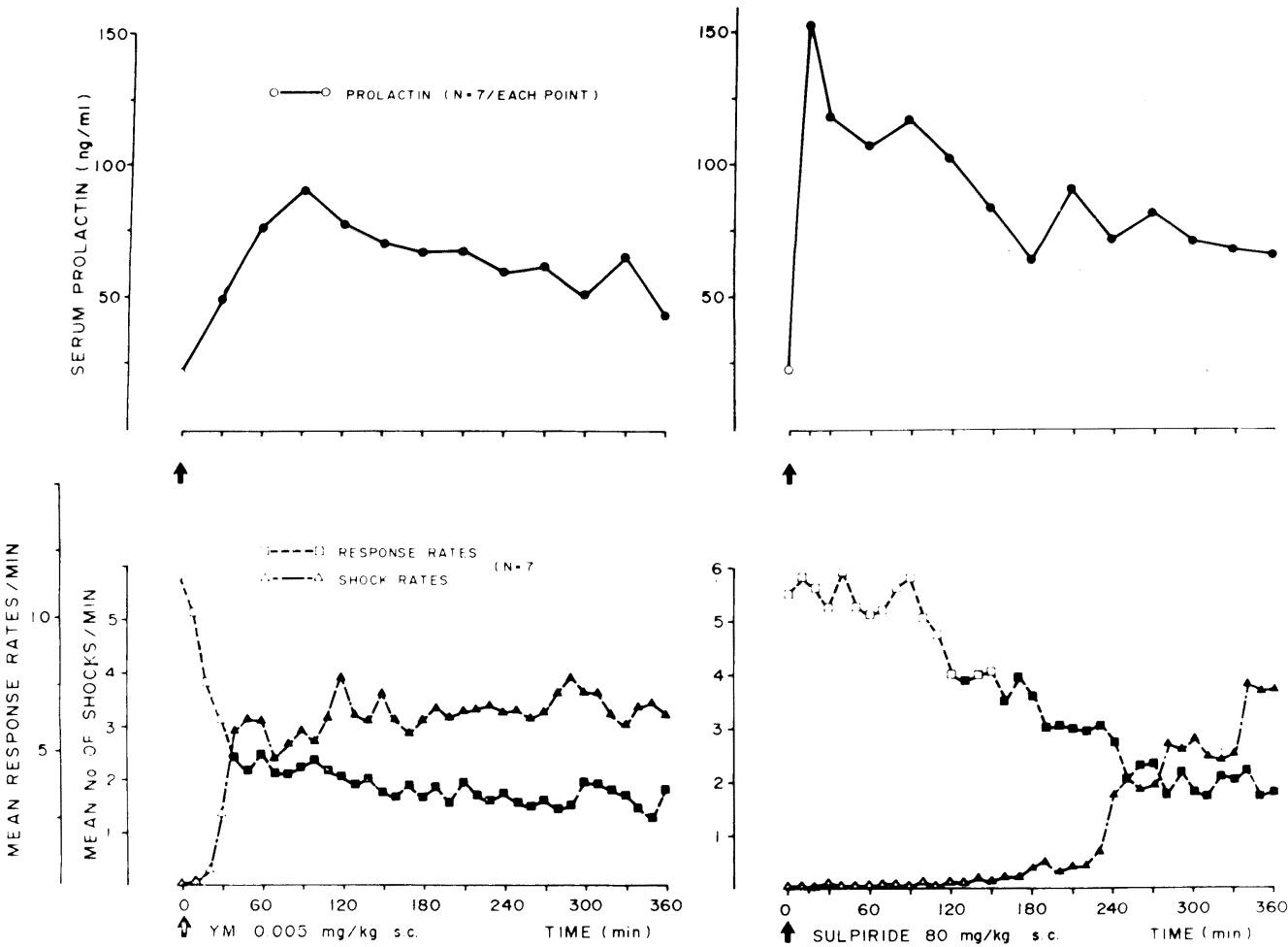

\section{$\uparrow$}

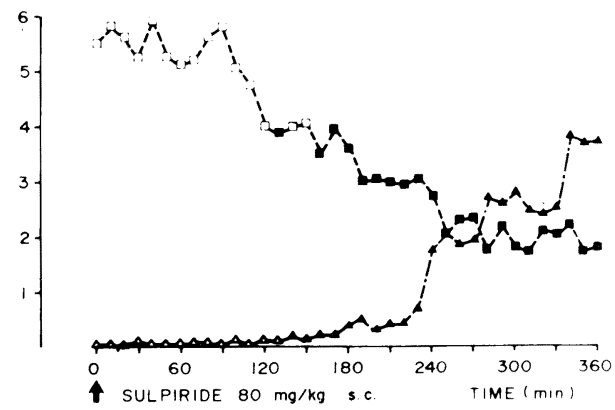

Fig. 3. Temporal changes in avoidance responses (lower panel) and serum prolactin levels (upper panel) after administration of benzamide derivatives: YM-09151-2 (0.005 mg/kg s.c.) (left panel) and sulpiride ( $80 \mathrm{mg} / \mathrm{kg} \mathrm{s.c.)} \mathrm{(right} \mathrm{panel).} \mathrm{The} \mathrm{data} \mathrm{are} \mathrm{shown} \mathrm{in} \mathrm{the} \mathrm{same} \mathrm{way} \mathrm{as} \mathrm{in} \mathrm{Fig.} 1$. No parallelism between temporal changes in avoidance responses and those in serum prolactin levels is observed after SP administration.

effect is thought to be due to a direct stereospecific blockade of dopamine receptors in the anterior pituitary gland (27-30).

The results obtained in the present study also indicate that the prolactin-increasing effect of antipsychotic drugs may be utilized as a determinant to predict antipsychotic potencies in human cases, excluding sulpiride treatment, even though hyperprolactinemia is one of the noticeable side effects in antipsychotic therapy.

\section{References}

1 Cook, L. and Catania, A.C.: Effects of drugs on avoidance and escape behavior. Fed. Proc. 23, 818-835 (1964)

2 Cook, L. and Kelleher, R.T.: Drug effects on the behavior of animals. Ann. N.Y. Acad. Sci. 96, 315-335 (1962)

3 Meltzer, H.Y., Fang, V.S., Fessler, R., Simonovic, M. and Stanisic, D.: Neuroleptic-stimulated prolactin secretion in the rat as an animal model for biological psychiatry: 1. Comparison with anti-psychotic activity. In Animal Models in Psychiatry and Neurology, Edited by Hanin, I. and Usdin, E., p. 443-455, Pergamon Press, New York (1977)

4 Langer, G., Sacher, E.J., Halpern, F.S., Gruen, P.H. and Solomon, M.: The prolactin response to neuroleptic drugs. A test of dopaminergic blockade: Neuroendocrine studies in normal men. J. Clin. Endocrinol. Metab. 45, 996-1002 (1977)

5 Hays, S.E., Poland, R.E. and Rubin, R.T.: Prolactin releasing potencies of antipsychotic and related nonantipsychotic compounds in female rats: Relation to clinical potencies. J. Pharmacol. Exp. Ther. 214, 362-367 (1980)

6 Clemens, J.A., Smalstig, E.B. and Sawyer, B.D.: Antipsychotic drugs stimulate prolactin release. Psychopharmacologia (Berlin) 40, 123-127 (1974)

7 Dunn, J.D., Arimura, A. and Scheving, L.E.: 
Effect of stress on circadian periodicity in serum $\mathrm{LH}$ and prolactin concentration. Endocrinology 90, 29-33 (1972)

8 Hayashi, T., Fujimoto, K. and Tadokoro, S.: Different effects of psychotropic drugs on operant behaviors maintained by different reinforcements in rats. Japan. J. Neuropsychopharmacol. 2, 191-201 (1980) (Abs. in English)

9 Hayashi, T., Tadokoro, S., Hashimoto, H. and Nakashima, M.: Enhancement of avoidancesuppressing effect after repeated administration of haloperidol and serum haloperidol in rats. Pharmacol. Biochem. Behav. 17, 131-136 (1982)

10 Hayashi, T., Fujimoto, K. and Tadokoro, S.: Different effects of psychotropic drugs on Sidman avoidance response owing to external stimulus control in rats. Japan. J. Psychopharmacol. 1, 13-19 (1981) (Abs. in English)

11 Kuribara, H. and Tadokoro, S.: Correlation between antiavoidance activities of antipsychotic drugs in rats and daily clinical doses. Pharmacol. Biochem. Behav. 14, 181-192 (1981)

12 Kuribara, $\mathrm{H}$. and Tadokoro, S.: Effects of cis- N(1-benzyl-2-methylpyrrolidin-3-yl)-5-chloro-2methoxy-4-methylaminobenzamide (YM-09151 2 ) on operant avoidance responses in rats. Folia Pharmacol. Japon. 77, 521-530 (1981) (Abs. in English)

13 Usuda, S., Nishikori, K., Noshiro, O. and Maeno, $\mathrm{H}$.: Neuroleptic properties of cis-N-(1-benzyl2-methylpyrrolidin-3-yl)-5-chloro-2-methoxy4-methylaminobenzamide (YM-09151-2) with selective antidopaminergic activity. Psychopharmacology (Berlin) 73, 103-109 (1981)

14 Birge, C.A., Jacobs, L.S., Hammer, C.T. and Daughaday, W.H.: Catecholamine inhibition of prolactin secretion by isolated rat adenohypophyses. Endocrinology 86, 120-130 (1970)

15 Horowski, R. and Graf, K.-J.: Influence of dopaminergic agonists and antagonists on serum prolactin concentrations in the rat. Neuroendocrinology 22, 273-286 (1976)

16 Lal, S., de la Vega, C.E., Sourkes, T.L. and Friesen, H.G.: Effect of apomorphine on growth hormone, prolactin, $\mathrm{LH}$ and $\mathrm{FSH}$ levels in human serum. J. Clin. Endocrinol. Metab. 37, 719-724 (1973)

17 Macleod, R.M. and Lehmeyer, J.E.: Studies on the mechanism of the dopamine-mediated inhibition of prolactin secretion. Endocrinology 94, 1077-1085 (1974)

18 Meltzer, H.Y., Fessler, R.G., Simonovic, M. Doherty, J. and Fang, V.S.: Effect of $d$ - and Iamphetamine on rat plasma prolactin levels. Psychopharmacology (Berlin) 61, 63-69 (1979)
19 Ravitz, A.J. and Moore, K.E.: Effects of apomorphine, methylphenidate and cocaine on serum prolactin concentrations in the male rat. Life Sci. 21, 267-272 (1977)

20 Shaar, C.J. and Clemens, J.A.: The role of catecholamines in the release of anterior pituitary prolactin in vitro. Endocrinology 95, 1202-1212 (1974)

21 Smalstig, E.B., Sawyer, B.D. and Clemens, J.A.: Inhibition of rat prolactin release by apomorphine in vivo and in vitro. Endocrinology 95, 123-129 (1974)

22 Terai, M., Usuda, S., Kuroiwa, I., Noshiro, O. and Maeno, H.: Selective binding of YM-09151-2, a new potent neuroleptic, to $D_{2}$-dopaminergic receptors. Japan. J. Pharmacol. 33, 749-755 (1983)

23 Honda, F., Satoh, Y., Shimomura, K., Satoh, H., Noguchi, H., Uchida, S. and Kato, R.: Dopamine receptor blocking activity of sulpiride in the central nervous system. Japan J. Pharmacol. 27, 397-411 (1977)

24 Hopf, A. and Dross, K.: Comparative studies on the metabolism and distribution of sulpiride and sultopride. In Biological Psychiatry Today, Edited by Obiols, J., Ballus, C., Gonzalez Monclus, E. and Pujol, J., p. 1020-1024, Elsevier/ North-Holland Biomedical Press, Amsterdam (1979)

25 Benakis, A. and Rey, C.: Autoradiographic study of ${ }^{14} \mathrm{C}$-sulpiride in mice and rats. Specific localization in the hypophysis of rats after single and repeated administrations. J. Pharmacol. 7, 367-378 (1976)

26 Bjerkenstedt, L., Harnryd, C. and Sedvall, G.: Effect of sulpiride on monoaminergic mechanisms on psychotic women. Psychopharmacology (Berlin) 64, 135-139 (1979)

27 Hofmann, M., Jommi, G.C., Montffusco, O., Tonon, G.C., Spano, P.F. and Trabucchi, M.: Stereospecific effects of $(-)$ sulpiride on brain dopamine metabolism and prolactin release. J. Neurochem. 32, 1547-1550 (1979)

28 Muller, E.E., Stefanini, E., Camanni, F., Locatelli, V., Massara, F., Spano, P.F. and Cocchi, D.: Prolactin releasing effects of sulpiride isomers in rats and man. J. Neural. Transm. 46, 205-214 (1979)

29 Theodorou, A., Crockett, M., Jenner, P. and Marsden, C.D.: Specific binding of $\left({ }^{3} \mathrm{H}\right)$ sulpiride to rat striatal preparations. J. Pharm. Pharmacol. 31, 424-426 (1979)

30 Theodorou, A., Hall, M.D., Jenner, P. and Marsden. C.D.: Cation regulation differentiates specific binding of $\left({ }^{3} \mathrm{H}\right)$ sulpiride and $\left({ }^{3} \mathrm{H}\right)$ spiperone to rat striatal preparations. J. Pharm. Pharmacol. 32, 441-444 (1980) 